\title{
Geophysical Investigation of a Solid Waste Disposal Site Using Integrated Electrical Resistivity Tomography and Multichannel Analyses of Surface Waves Methods
}

\author{
Ruobai Zhao', Neil Anderson², Jing Sun ${ }^{3}$ \\ ${ }^{1}$ Department of Geosciences and Geological and Petroleum Engineering, Missouri University of Science and Technology, Rolla, \\ MO, USA \\ ${ }^{2}$ Department of Geosciences and Geological and Petroleum Engineering, Missouri University of Science and Technology, Rolla, \\ MO, USA \\ ${ }^{3}$ Department of Mathematics and Statistics, Missouri University of Science and Technology, Rolla, MO, USA \\ Email:rzmqc@mst.edu
}

How to cite this paper: Zhao, R., Anderson, N., \& Sun, J. (2020). Geophysical Investigation of a Solid Waste Disposal Site Using Integrated Electrical Resistivity Tomography and Multichannel Analyses of Surface Waves Methods. Journal of Geoscience and Environment Protection, 8, 55-69.

https://doi.org/10.4236/gep.2020.83005

Received: February 10, 2020

Accepted: March 21, 2020

Published: March 24, 2020

Copyright ( 2020 by author(s) and Scientific Research Publishing Inc. This work is licensed under the Creative Commons Attribution International License (CC BY 4.0).

http://creativecommons.org/licenses/by/4.0/

\begin{abstract}
Electrical resistivity tomography survey was deployed at a solid waste landfill in southwest Missouri USA with the intent to map variations in moisture content through the solid waste and underlying subsurface, and to map the top of bedrock. Multichannel analyses of surface waves survey was also deployed to map variations in engineering properties of the solid waste and underlying subsurface, and to constrain the interpretations of top of bedrock. The 2-D resistivity images through the waste suggest rainwater seeps through the cap cover system of the solid waste landfill, and moisture content within the solid waste increases with solid waste burial depth. The resistivity anomalies displayed by the soil and bedrock directly underneath the solid waste suggests a lateral component to moisture infiltrating at the toe of the landfill, which is flowing inward to the base of solid waste structural low. The 1-D shear wave velocity profiles obtained from the multichannel analyses of surface waves survey helped interpret the top of bedrock underneath the solid waste, where top of bedrock is difficult to map using electrical resistivity tomography, as shallow fractured bedrock is moist and displays comparable resistivity values to that of overlying soil. Not surprisingly, the top of bedrock is readily identified on the electrical resistivity tomography profiles in places where subsurface is relatively dry. The deployment of the combined noninvasive, cost and time effective geophysical surveys, along with engineering judgement on available site history data, has reasonably identified potential
\end{abstract}


landfill seepage pathways. The methodology presented could be used in similar site investigation settings.

\section{Keywords}

Electrical Resistivity Tomography, Electrical Resistivity Imaging,

Multichannel Analyses of Surface Waves, CCR, Solid Waste Landfill,

CCR Landfill, ERT, ERI, MASW

\section{Introduction}

Many argue that without strict regulations to enforce the safe containment of solid waste in landfills, waste materials that contain hazardous elements could potentially cause harm to humans, animals, and the environment by contact. The public has long voiced their concerns over solid waste landfills regarding their safety and environmental impact. It is generally accepted that enforcing more stringent regulations regarding the placement, design, monitoring, and reporting of solid waste landfill will help prevent or minimize their potential negative impacts (e.g., contamination to groundwater, structure failure). This research was inspired and prompted by the increasing need from solid waste landfill owners, especially those who operate on karst terrains, to obtain effective and accurate assessments over their sites on landfill liner integrity studies and groundwater pollution potential studies.

Commonly used geotechnical borehole logging, if utilized as the primary tool, might not be sufficient in this type of investigation. Traditional borehole logging aid engineers in understanding the subsurface material distribution by providing actual information of the subsurface, however, it generally requires extensive time, labor, and cost to thoroughly investigate large areas of land. Sometimes, if the geology of the subject area is not very well known or fairly uniform, it could be difficult to characterize and generate continuous and extensive profile of the investigating subsurface.

The utilization of the modern geophysical investigation techniques, Electrical resistivity tomography (ERT) and Multichannel analyses of surface waves (MASW) were determined to be able to fulfill this gap with several advantages over other investigation techniques. Firstly, the mentioned two techniques could be deployed with time-effective data acquisition, processing, and interpretation systems, which facilitates the landfill assessment. Secondly, the two techniques are non-invasive and cause no damage to the containment of the landfill (e.g., integrity of landfill cover and liners.) Thirdly, the two techniques have been proved to be effective for karst terrain investigations, in other words, sensitive to moisture content in the subsurface thus giving good visual on seepage trend. Lastly, the two techniques are cost-effective. Solid waste landfills often take up a large area of land hence requires relatively more investigation time and labor. With this 
regard, ERT and MASW data acquisitions can be conducted fairly quickly covering large areas of investigated surface and acquired ERT and MASW data can be processed and interpreted within reasonable periods of time, provided that the interpreter is experienced, and constraints are available.

The intent of the study is to map the variations in moisture content and engineering properties of the solid waste, soil, and rock, and to map the top of bedrock. Utilizing both ERT and MASW geophysical techniques provides reliable results by analyzing correlations between ERT data and MASW data. The combined output from ERT and MASW are quality 1-D, 2-D models of the subsurface, where the bedrock depth, soil thickness, moist content variations, possible seepage pathways, and karst features could be identified.

\section{Waste Containment}

Solid waste landfills are regulated under subtitle D of the Federal Resource Conservation and Recovery Act (RCRA). Several systems are essential in a solid waste landfill to the containment of the solid waste (Figure 1). A low-permeability cap (also called "final cover", "final cap", or "cap cover"), is normally installed as part of the post-closure care, and comprises of several layers to effectively contain the solid waste and minimize human/animal contact, and to minimize rainwater infiltration into the solid waste. In the leachate collection system installed beneath the solid waste, potential infiltrated leachate is collected in a drainage layer and drained out through drainage pipes either by pumping or by gravity. A bottom liner system (ideally a composite liner) is installed below the leachate collection system and is normally the last barrier to prevent any leftover infiltrated leachate from seeping further into the underlying soil and bedrock. The landfill is periodically monitored for groundwater contamination through the installation of upgradient and down-gradient monitoring wells and sampling.

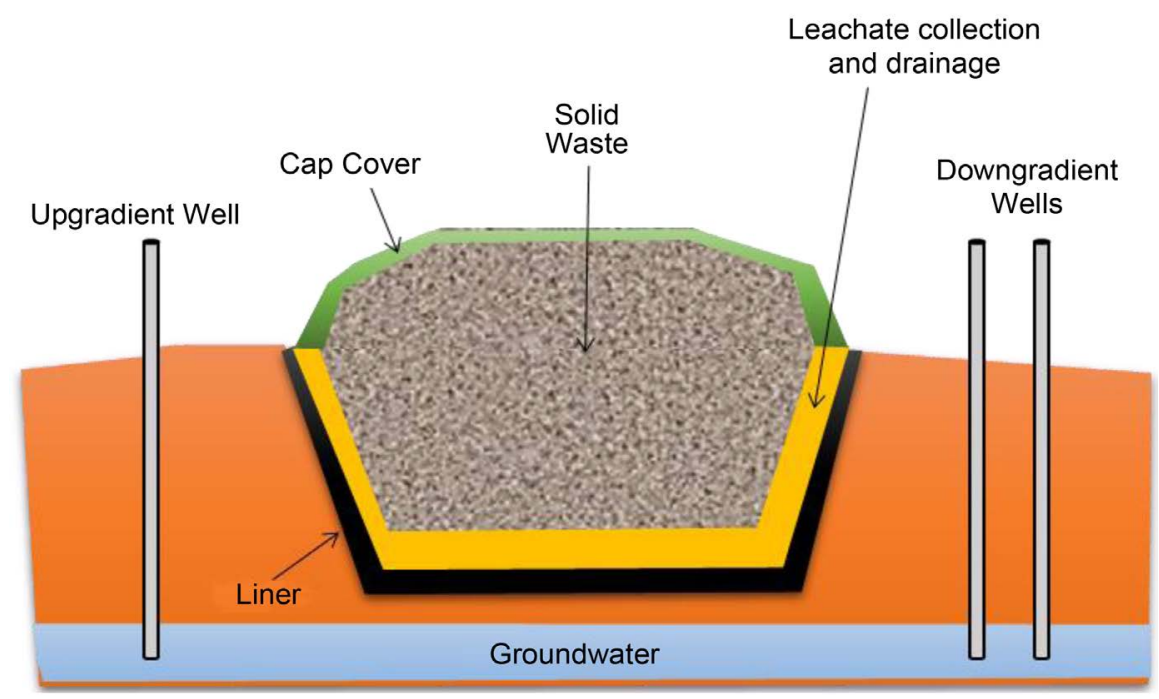

Figure 1. A solid waste landfill is comprised of several systems (Tenenbaum, 2009). 


\subsection{Cap Cover System}

Depending on the location of the solid waste landfill and then-effective regulations governing the design criteria, the cap cover system can vary from site to site. It can also vary in the same site, when a newer cap with a different design can be installed upon waste that was added onto the older cap during a vertical expansion. The cap cover system generally comprises of several layers (Figure 2). Typically, a soil layer with vegetation on top is utilized as the uppermost erosion layer. The vegetation serves as erosion control and reduces water infiltration by evapotranspiration, while the soil layer serves as a protective layer and the nutrition source for vegetation growth (Shanahan, 2004).

The infiltration layer is also termed as the "low permeability" layer and is installed above the solid waste and utilizes low permeability materials to prevent or minimize water infiltration into the solid waste (Figure 2). For the specific site in this study, the RCRA does not require a composite system for this layer, provided that the permeability requirement is met $\left(\mathrm{K}<1 \times 10^{-5} \mathrm{~cm} / \mathrm{s}\right)$.

Ideally, a drainage layer and a filter layer are installed between the topsoil layer and the infiltration layer (Figure 2). By gravitationally draining away water that has infiltrated through the upper soil, the amount of rainwater seeping down onto the infiltration layer is reduced. The drainage layer is usually constructed at an angle to utilize gravity for drainage, and the fluid is discharged along the landfill flanks and to the toe. To prevent the drainage layer from clogging, the filter layer that is normally made of geosynthetic filter fabric or sand filters out the soil fines coming from the soil layer, which could potentially clog the drain.

\subsection{Leachate Collection System}

It is not surprising to see some rainwater still infiltrates into the solid waste through the cap cover, and for this reason, solid waste landfills are usually

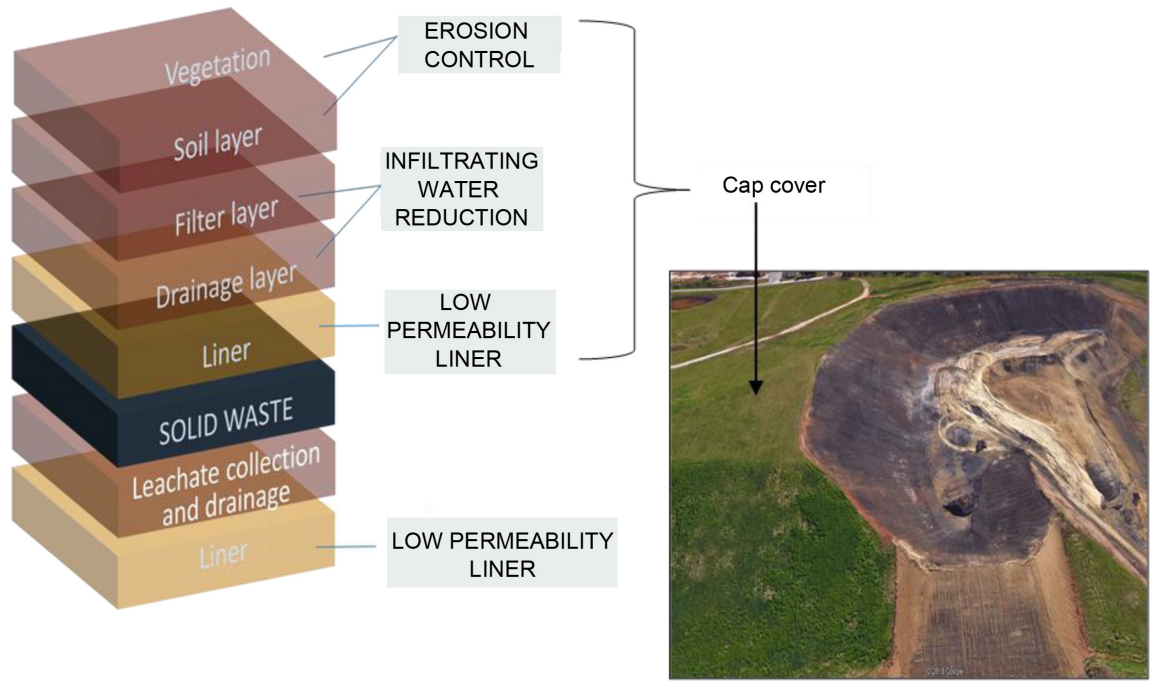

Figure 2. Typical solid waste landfill layer system. 
equipped with leachate collection systems (Figure 2), in order to collect and drain out any infiltrated rainwater. The leachate collection system uses materials that have sufficient strength and thickness to support the above solid waste structure.

The leachate is drained through a drainage layer, commonly installed beneath the waste. The drainage layer is normally made of geocomposite with perforated pipes. The leachate is then pumped into a leachate collection pond. Since the bottom liner system underlies the leachate collection layer and acts as the last barrier between leachate and subsurface, the leachate collection system must maintain an effective drain to prevent or minimize the amount of leachate head forced upon the bottom liner system.

\subsection{Bottom Liner System}

The bottom liner system (Figure 2) can be either a single layer system (e.g., a single clay layer), or a composite liner system. A composite liner system generally performs better in terms of preventing leachate seepage. The bottom liner system installed below the drainage layer is normally the last barrier to prevent any leftover infiltrated leachate from seeping further down into the underlying soil and bedrock.

\section{Study Area}

\subsection{Geology}

The solid waste landfill site is located in Green County, Missouri, USA (Figure 3), which is situated on the Springfield Plateau, where land is underlain by Paleozoic carbonate rocks that are susceptible to karstification.

The local bedrock is comprised of Mississippian limestones that are mainly limestones with intercalated beds of chert and impure flint, and some sandstones and shales (Shepard, 1898). The uppermost and surface bedrock unit is the Osagean series Burlington-Keokuk limestone, which is susceptible to karstification. Boring control, MASW (multichannel analysis of surface waves) control and

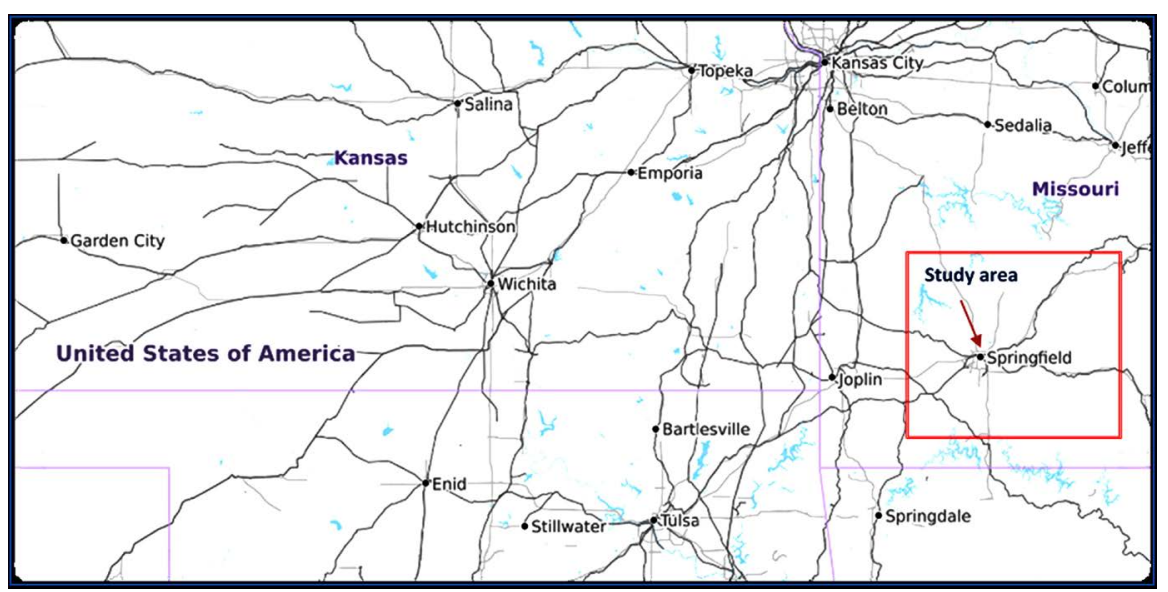

Figure 3. Study area (OpenStreetMap contributors, 2015). 
ERT control data in the area have suggested the upper Burlington-Keokuk limestone is pervasively fractured in the general study area. The Burlington-Keokuk limestone is overlain by unconsolidated residual materials that comprise red clay, silt, and rock fragments as a result of bedrock weathering (Vandike \& Sherman, 1994). Under the Burlington-Keokuk limestone is the Elsey and Reeds-Spring limestone, which comprises of Osagean series carbonates and cherty carbonates and is underlain by the Pierson Formation.

\subsection{Site History}

Site history indicates that the topography around the landfill is such that incoming flow only comes from north of the landfill, and the incoming flow is diverted by man-made berms to flow away from the landfill, so such water does not get contact with landfill. The infiltration layer in the cap cover system, as well as the bottom liner system is single layer systems with designs in accordance with local regulations. Rainwater mostly flows down along the landfill shoulder.

The solid waste in the study site is comprised of mostly fly ash, one of the byproducts that are produced or left behind in the coal boiler in the coal combustion process (Figure 4). According to the American Coal Ash Association (ACAA, 2016), approximately $80 \%$ of the byproducts produced is fly ash. The byproducts generally consist of a significant portion of the mineral matter in the coal that is incombustible, while carbon and other combustible elements in the coal are oxidized or volatilized (William, Thiery, Schuller, \& Subway, 1981). Fly ash is widely reused in the civil industry, for example, to make geopolymers. Research done by Kang et al. (2019) stated that fly ash particles were found to collide with the kaolinite particles during settling and form large agglomerates, therefore the settling rate of fly ash-soil mixture increased with the addition of fly ashes.

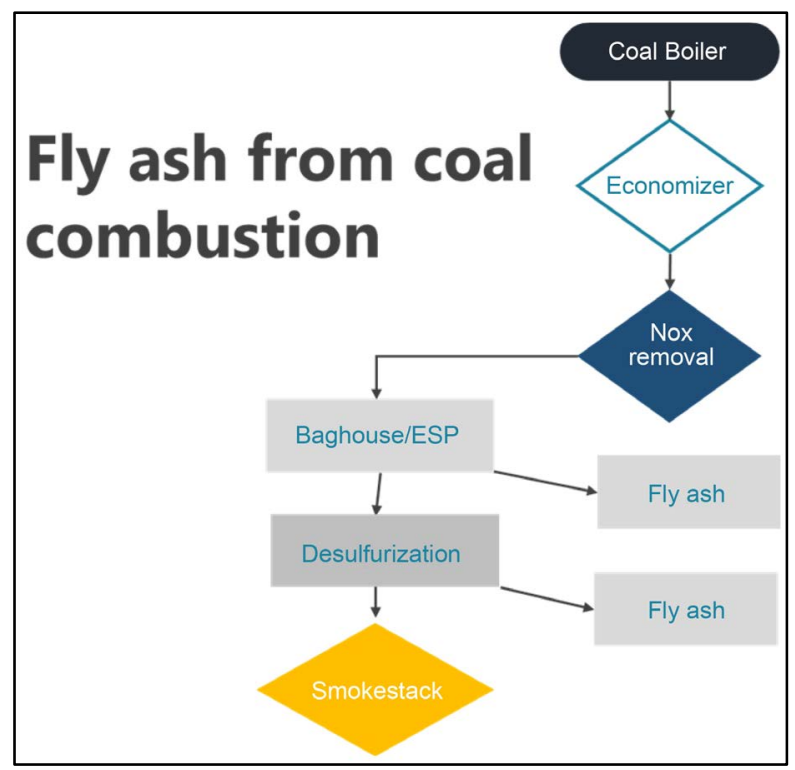

Figure 4. Fly ash production process during coal combustion (Butalia, 2011). 
In addition to fly ash, other byproducts such as bottom ash and flue gas desulfurization (FGD) materials are also present in the waste. Bottom ash is the ash found at the bottom of dry bottom coal boiler, which is a fine to coarse material and consists of dark agglomerated ash particles. These particles are not small enough to be carried away by swirling air designed to transport unburned ash out of the coal boiler and hence accumulated at the bottom of the boiler (University of Kentucky Center for Applied Energy Research, 2017). Flue gas desulfurization (FGD) materials are produced in the air pollution control system, usually a "scrubber," which sprays fine-ground sorbents such as limestone or lime onto flue gas to remove sulfur oxides. The limestone or lime reacts with the sulfur to form calcium sulfite that is processed to make FGD or synthetic gypsum. This by-product is predominantly silt-size particles (University of Kentucky Center for Applied Energy Research. 2017).

\section{Data Preparation}

In this study, two types of geophysical surveys were deployed. Electrical resistivity tomography (ERT) data were acquired with $5 \mathrm{ft}(1.5 \mathrm{~m})$ electrode spacing, along west-east oriented traverses that exceeded $1300 \mathrm{ft}$ (396 m) on the northern part of solid waste, where it had ceased to accept new solid waste and was covered with a cap cover system. The primary equipment included an automated 8-channel resistivity meter AGI SuperStingR8 system, several deep-cycle marine batteries, two switch boxes, multiple ERT cables with electrodes attached, a large number of stainless-steel stakes and a laptop (Zhao \& Anderson, 2018). Software RES2DINV was used to process the ERT field data and generate 2-D resistivity profiles for interpretation. Multichannel analyses of surface waves (MASW) data were acquired using a 24-channel Seistronix seismograph with $4.5 \mathrm{~Hz}$ geophones, at the top of the solid waste landfill. Software SurfSeis was used to process the MASW field data and generate 1-D shear wave velocity profiles for interpretation.

\subsection{ERT Data Acquisition and Processing}

Two ERT profiles A and B were acquired along west-east oriented traverses (Figure 5). With the understanding that the order of electrode spacing affects the lateral resolution on the ERT profile and lateral resolution generally decreases with increasing depth, vertical resolution also decreases with increasing depth and is comparable to lateral resolution, the minimum length of the ERT array was determined to be $835 \mathrm{ft}(255 \mathrm{~m})$ by using 8 ERT cables with 168 electrodes. Electrodes were kept at a $5 \mathrm{ft}(1.5 \mathrm{~m})$ spacing. As illustrated in Figure 6, the resistivity meter controls the electrodes (e.g., injecting current and measuring voltage) by attaching to two switch boxes, and cables 1 to 4 being switched by switch box 1 while cables 4 to 8 being switched by switch box 2 (Zhao \& Anderson, 2018).

The maximum investigating coverage is achieved only in the central third of 


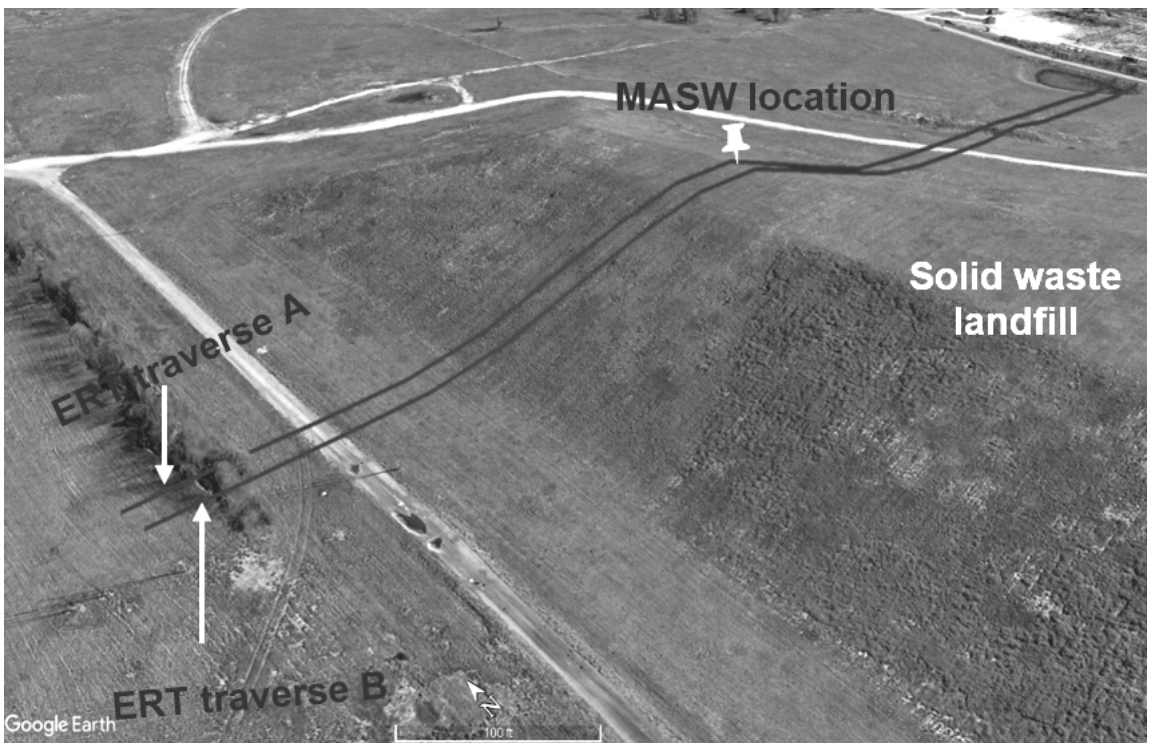

Figure 5. ERT traverses and MASW acquisition location at the landfill.

\section{$\therefore$ ERT Cable Layout}

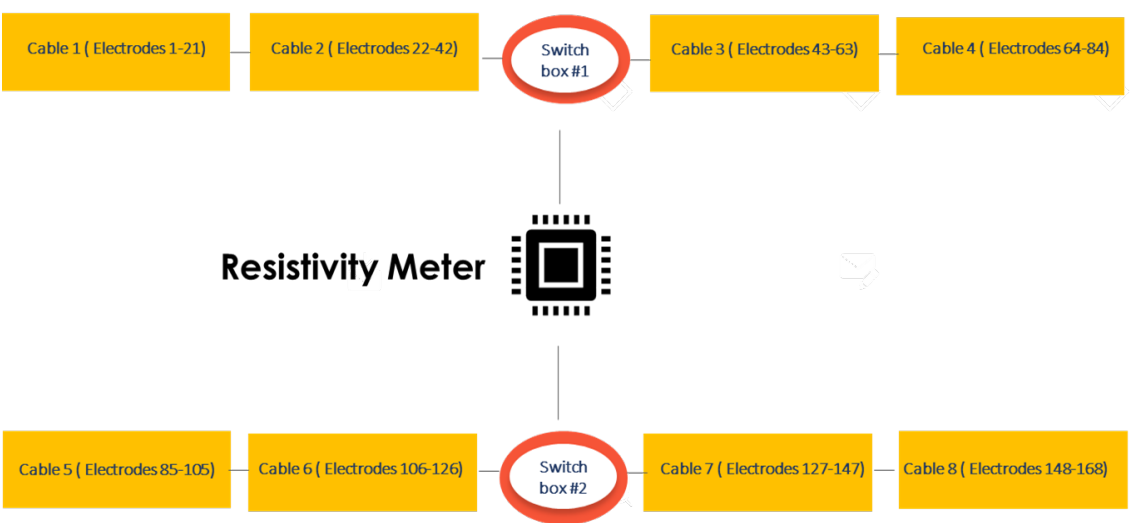

Figure 6. ERT cables and equipment layout.

the ERT array. In order to achieve the full length of the traverse that exceeded $1300 \mathrm{ft}$ (396 m) long, "rolled alongs" of the ERT cables were conducted.

The maximum achievable depth of investigation is usually $20 \%$ of the ERT array length (distance between the very first electrode and the very last electrode). In this study, the investigation depth was approximately $170 \mathrm{ft}(52 \mathrm{~m})$. A dipole-dipole array was utilized for all the ERT profiles, with the consideration that this type of array, compared to other arrays, provides excellent lateral resistivity contrast with reasonably faster acquisition time.

Raw ERT data (apparent resistivity data) acquired at the site were processed using software RES2DINV. The RES2DINV software was used to invert the acquired apparent resistivity data and generate an optimum resistivity image of the investigation target. Model parameters were estimated based on the observed 
data, and the model response was synthetic data that can be calculated from the mathematical relationships defining the model for a given set of model parameters (Loke, 2004). The mathematical link between the model parameters and the model response for the 2-D and 3-D resistivity models is provided by the finite-difference (Dey \& Morrison, 1979) or finite element methods (Silvester \& Ferrari, 1990). The output is 2-D electrical resistivity image of the subsurface. An estimate of the extent to which the output 2-D image correlates with the input apparent resistivity data is provided as a percent error.

\subsection{MASW Data Acquisition and Processing}

MASW data were acquired on the $500 \mathrm{ft}(155 \mathrm{~m})$ mark of the ERT traverse (Figure 5) using a 24-channel Seistronix seismograph with $4.5 \mathrm{~Hz}$ geophones placed at $5 \mathrm{ft}(0.6 \mathrm{~m})$ intervals to achieve an investigation depth of approximately $100 \mathrm{ft}(30 \mathrm{~m})$ (Figure 7). A $20 \mathrm{lb}$. sledgehammer was used as the source to generate the wave energy. Multiple MASW profiles were employed at mostly 200 $\mathrm{ft}(61 \mathrm{~m})$ intervals. The investigating depth of the MASW survey is roughly the same as the geophone array length, which is approximately $100 \mathrm{ft}(30 \mathrm{~m})$. The acquired data were checked frequently, and $2.5 \mathrm{ft}(0.8 \mathrm{~m})$ geophone spacing was used instead if the data set with $5 \mathrm{ft}(1.5 \mathrm{~m})$ spacing did not provide a quality result. The Seistronix seismograph and laptop were placed at the back of the vehicle so that equipment can be transferred to the next location fairly quickly.

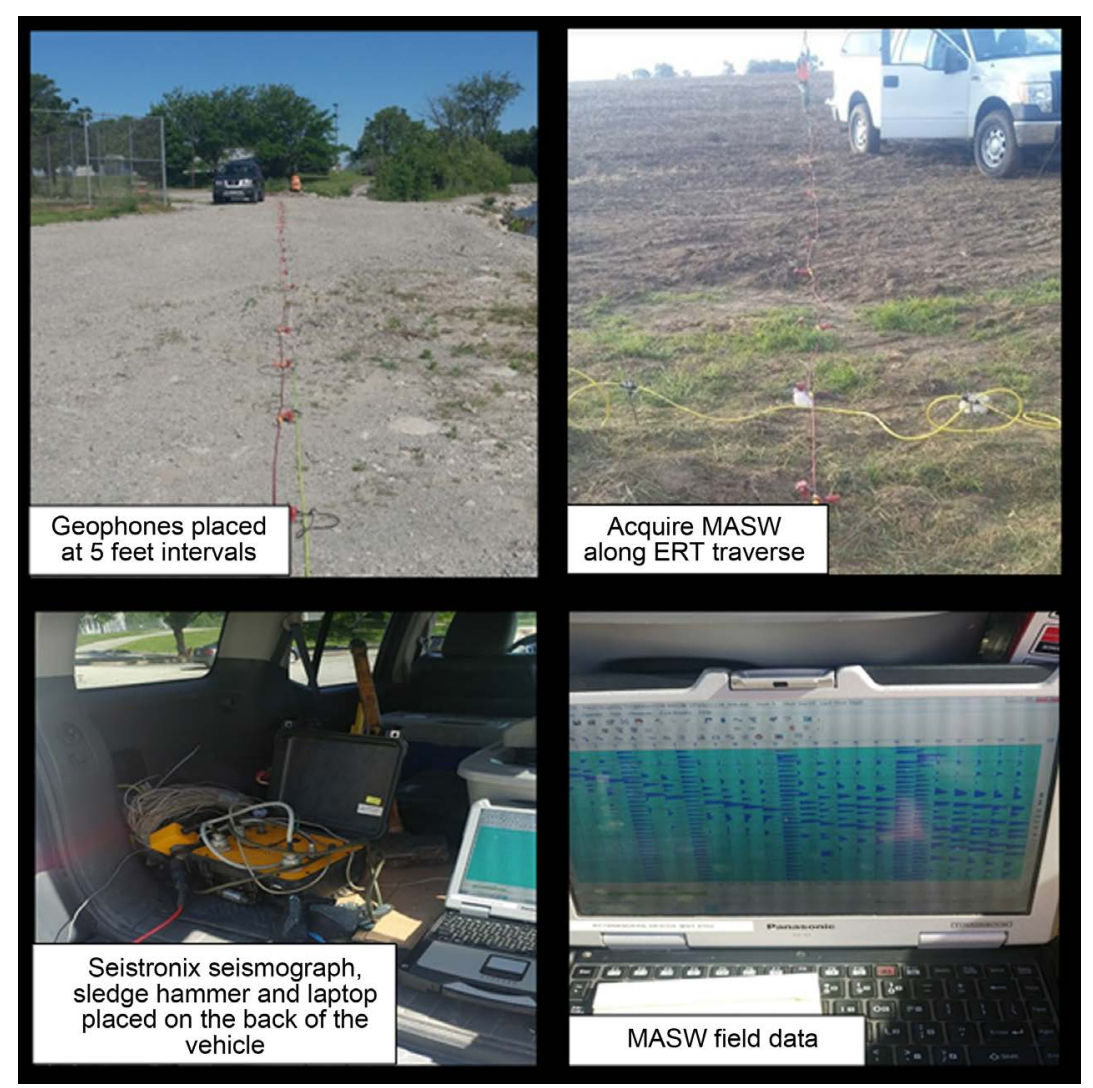

Figure 7. MASW data acquisition and field processing (Zhao, 2018). 
MASW field data was processed using software SURFSEIS. The fundamental-mode dispersion curves were estimated for each record. The curves then were inverted to obtain 1-D (depth) vs. (shear-wave velocity) profiles (Kansas Geological Survey, 2014).

\section{Results and Discussions}

ERT profile $A B$ is a processed resistivity image representing the subsurface midway of stitched ERT profile A, B (Figure 8). The top of bedrock underneath the solid waste cannot be mapped with confidence, as the subsurface bedrock and soil are anomalously moist and do not have a distinctive resistivity contrast. To better interpret the top of bedrock, MASW data was acquired at the $507 \mathrm{ft}$ (155 m) mark on the ERT traverse to constrain the interpretation of top of bedrock at this location, and the top of bedrock obtained from shear wave velocity profile is superposed on the ERT profile AB. The top of rock in other places where bedrock and is relatively dry is readily identified on ERT profile AB and correlates well with the $125 \mathrm{ohm}-\mathrm{m}$ resistivity interval. The interpretation of top of the bedrock also relies on the general topographic trends of the area. In the end, the top of bedrock is interpreted for the whole profile and is marked in black line.

Based on MASW control data acquired elsewhere in the general study area, the subsurface rock in the study area typically has a shear-wave velocity ranges from $1500 \mathrm{ft} / \mathrm{s}$ to over $5000 \mathrm{ft} / \mathrm{s}$, which indicates that the shallower bedrock is

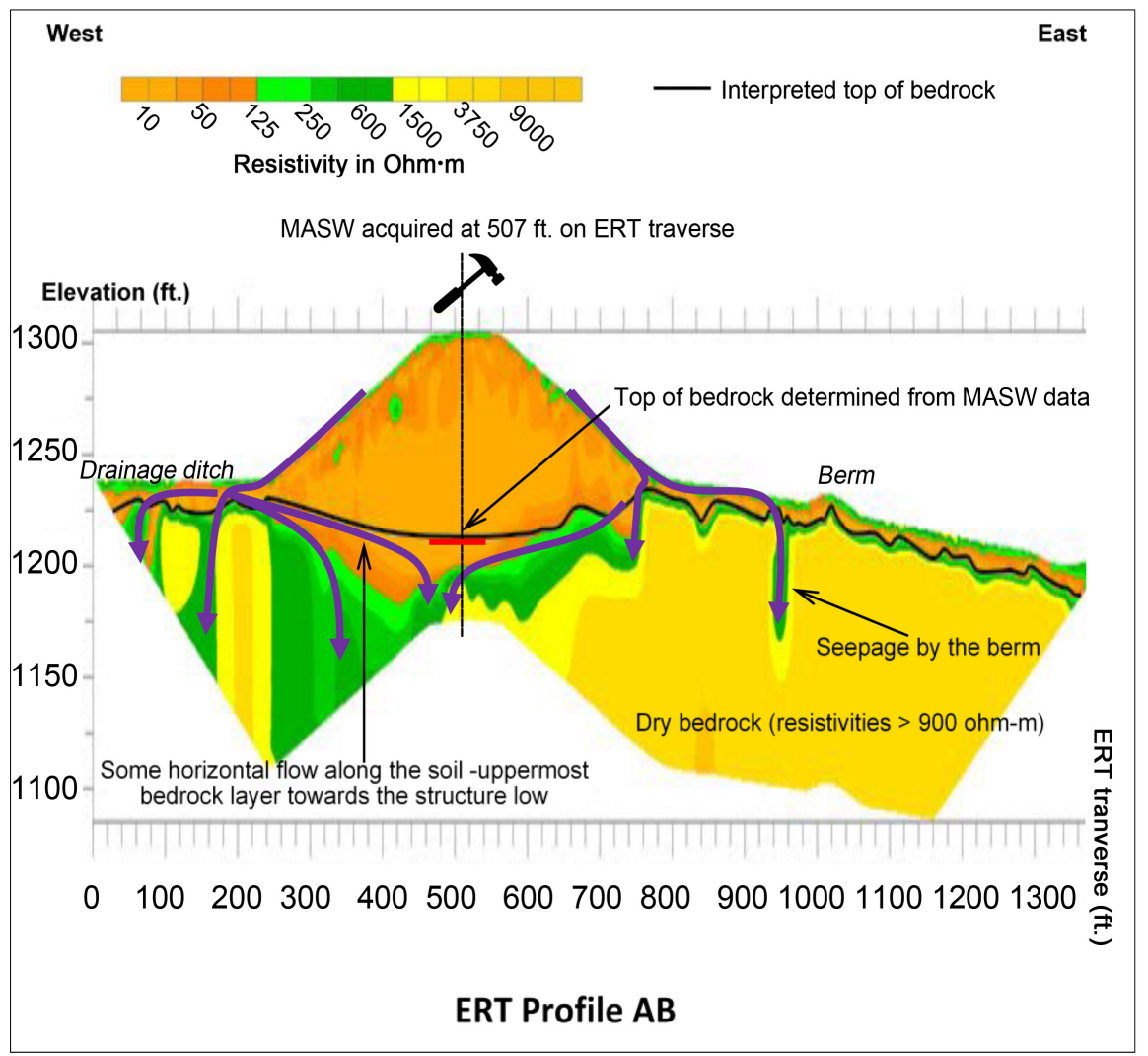

Figure 8. Processed ERT profile AB. 
likely pervasively fractured, and the deeper bedrock is relatively intact. On the acquired MASW profile (Figure 9), soil and solid waste are generally characterized by shear wave velocity ranges from $400 \mathrm{ft} / \mathrm{s}$ to over $3000 \mathrm{ft} / \mathrm{s}$. Shear wave velocity increases with solid waste burial. It is difficult to identify soil and solid waste based on shear wave velocity or resistivity.

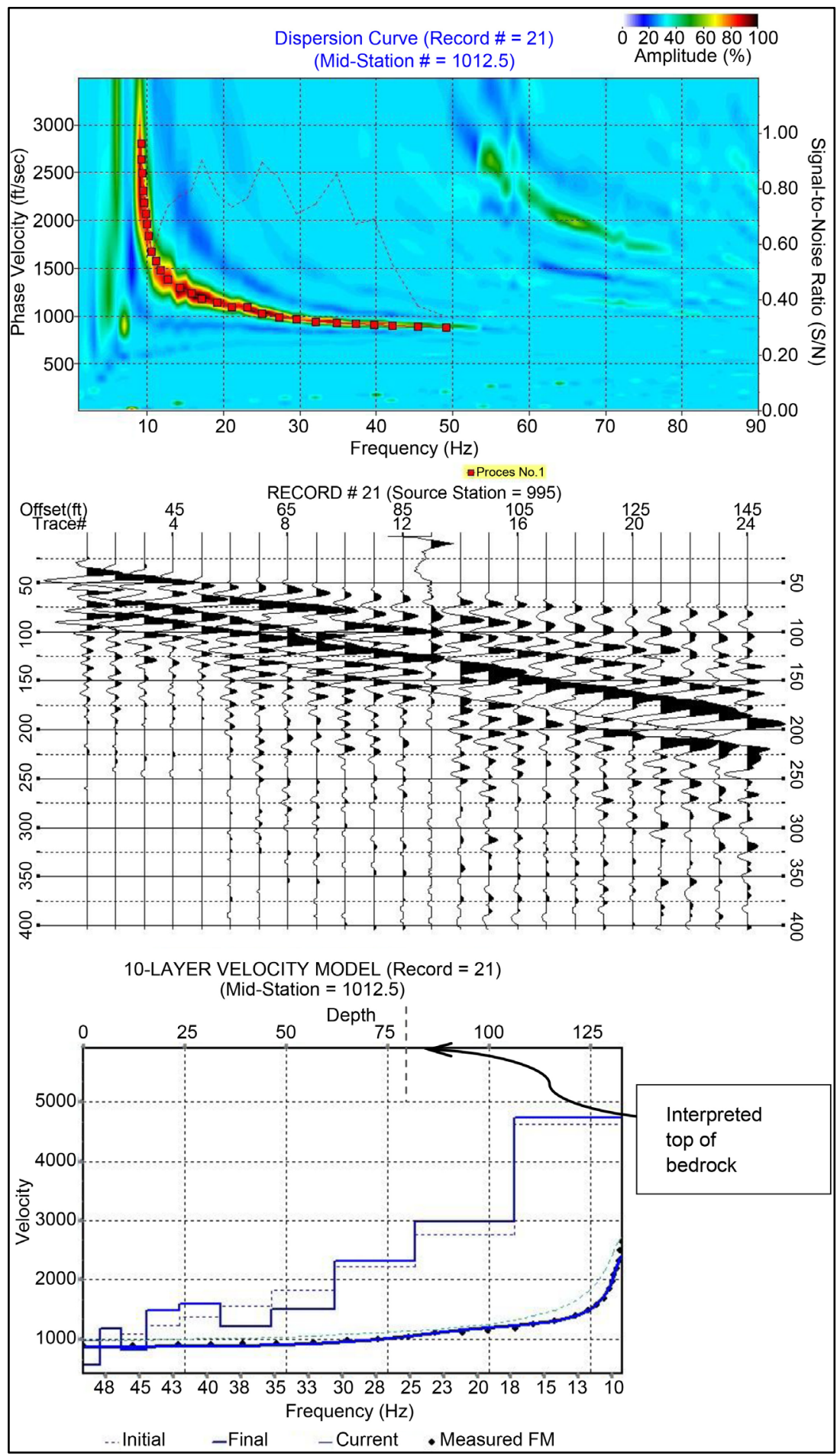

Figure 9. Processed MASW profile acquired at the $507 \mathrm{ft}$ mark on ERT profile AB. 
The solid waste/clay liner, clay liner/soil and soil/rock contacts beneath the landfill cannot be confidently mapped using ERT data. Resolution of ERT layers is about 12 feet $(4 \mathrm{~m})$ and the upper rock beneath the solid waste is very moist and has comparable resistivity values to overlying moist soil and solid waste.

The resistivity values of the bedrock underneath the solid waste landfill is mostly represented by resistivity values of less than $900 \mathrm{ohm}-\mathrm{m}$, indicating relatively higher moisture content, as compared to the the east side of the landfill where bedrock is relatively dry and is mostly represented by resistivity values that are greater than $900 \mathrm{ohm}-\mathrm{m}$. Based on the design of the landfill, it appears that rainwater flowing along the flanks of the landfill infiltrated vertically at the toe of the landfill, and since the landfill is built on a south-trending channel, the moisture also seems to flow along the soil/bedrock contact towards the structure low at the base of the landfill.

The resistivity image of the solid waste is zoomed in and shown in Figure 10. The uppermost portion of the waste is generally dry and is characterized by resistivity values between approximately $50 \mathrm{ohm}-\mathrm{m}$ to $250 \mathrm{ohm}-\mathrm{m}$. Based on available site design data and the understanding of the components of the solid waste landfill, this portion is interpreted as the cap cover system. Below the interpreted cap cover, resistivity values of the solid waste decrease to approximately $10 \mathrm{ohm}-\mathrm{m}$ with increasing depth. Based on the understanding that the cap cover system placed on top of the waste does not prevent all the rainwater from infiltrating into the solid waste, it appears that rainwater has infiltrated through the cap cover system into the solid waste to the bottom liner.

However, as mentioned previously, site history has indicated that the solid waste disposed at the site mainly contains fly ash, bottom ash, and flue gas
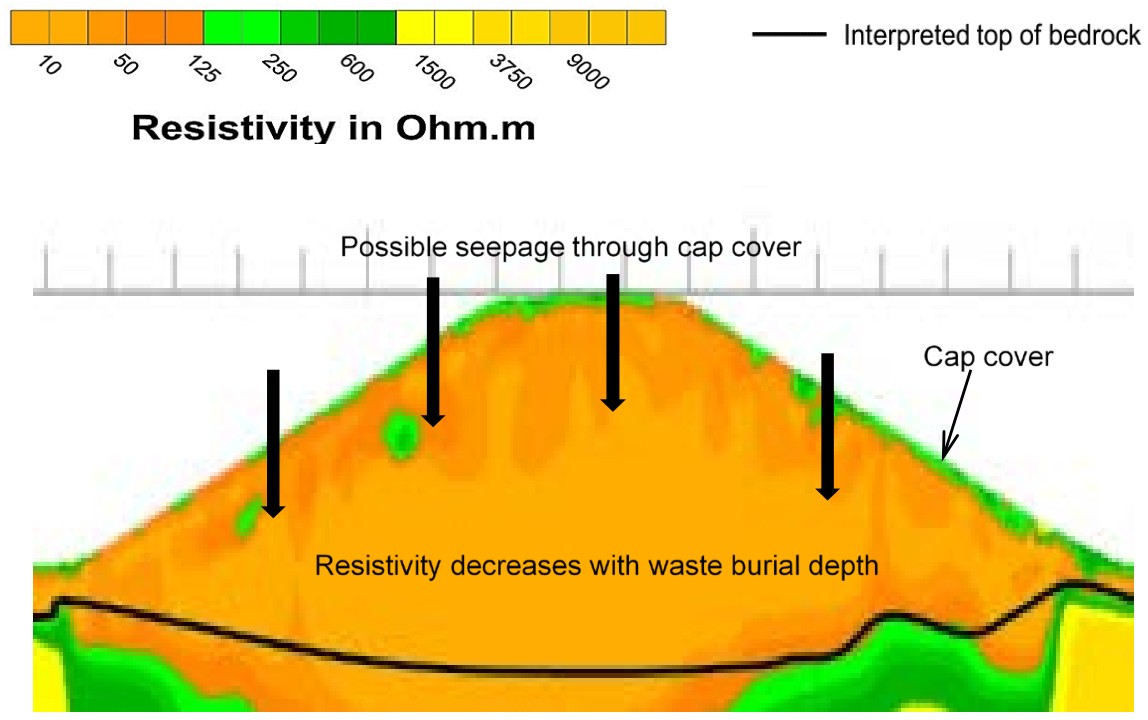

\section{Solid waste zoomed-in view}

Figure 10. Possible seepage through the cap cover system into the solid waste based on the resistivity distribution pattern. 
desulfurization (FGD) materials. Site history also indicates that bottom ash was disposed infrequently (every few years), and the waste in the landfill is mainly fly ash and FGD materials. When flue gas was produced, limestone or lime was added to the flue gas to act with sulfur; therefore it is reasonable to believe the waste contains a certain amount of calcium sulfate, which is the product of such desulfurization process. Calcium sulfate is conductive and the low resistivity values in the solid waste could also be the result of electronic conduction through calcium sulfate rather than electrolytic conduction through moisture content. Moreover, when the waste was piled up it contained moisture as a result of prewetting (part of the dust control process), which might also be the reason of the low resistivity values.

\section{Conclusion}

This research presents the use of two cost-effective, non-invasive and reasonably accurate geophysical investigation techniques to image a solid waste landfill. The non-invasive ERT caused no damage to the containment (e.g., cap cover, liner) of the landfill. The non-invasive MASW provided information about the engineering properties of the solid waste and caused no damage to the containment of the landfill.

The top of bedrock is identified on the ERT profile based on resistivity contrast, previous research of the area, and the aid from MASW data. The soil and bedrock underneath the solid waste display comparable resistivity values hence the top of the bedrock in these areas cannot be identified based on ERT profile, however, the MASW data acquired at this location was able to provide such information.

Soil and solid waste in the study area are generally characterized by shear wave velocity ranges from $400 \mathrm{ft} / \mathrm{s}$ to over $3000 \mathrm{ft} / \mathrm{s}$. Shear wave velocity increases with solid waste burial. On the other hand, rock is generally characterized by shear wave velocity ranges from $1500 \mathrm{ft} / \mathrm{s}$ to over $5000 \mathrm{ft} / \mathrm{s}$. And similarly, shear wave velocity increases with rock depth.

Some moisture could have infiltrated the solid waste and the low resistivity values in the solid waste could also be a result of the calcium sulfate content in the FGD materials. Moisture also infiltrated at the toe of the landfill along vertical pathways, with a lateral component to seepage both towards and away from the landfill.

It should be noted that the contact between the cap cover and the solid waste, and the contact between the bottom liner and soil cannot be confidently imaged using ERT, as materials between contacts display similar resistivity values. And in this investigation, it is generally difficult to identify and differentiate soil and the solid waste based on shear wave velocity or resistivity. For future research, a reasonable number of borehole loggings with minimum invasion could be used at these locations, to constrain the interpretation, if, the interfaces between the materials mentioned above are of investigation interest. 


\section{Acknowledgements}

Part of the materials contained in this paper was previously published in the first author's Ph.D. dissertation. Map data copyrighted OpenStreetMap contributors and available from https://www.openstreetmap.org.

\section{Conflicts of Interest}

The authors declare no conflicts of interest regarding the publication of this paper.

\section{References}

ACAA (2016). Fly Ash Production and Use with Percent. https://www.acaa-usa.org/Portals/9/Files/PDFs/2016-Charts.pdf

Butalia, T. S. (2011). Coal Combustion Products in Constructed Landfills. http://www.gseworld.com/content/documents/Coal_Ash_Seminar/Dr._Butalia.pdf

Dey, A., \& Morrison, H. F. (1979). Resistivity Modelling for Arbitrary Shaped Two-Dimensional Structures. Geophysical Prospecting, 27, 1020-1036. https://doi.org/10.1111/j.1365-2478.1979.tb00961.x

Kang, X., Xia, Z., Chen, R., Sun, H., \& Yang, W. (2019). Effects of Inorganic Ions, Organic Polymers, and Fly Ashes on the Sedimentation Characteristics of Kaolinite Suspensions. Applied Clay Science, 181, Article ID: 105220. https://doi.org/10.1016/j.clay.2019.105220

Kansas Geological Survey (2014). http://www.kgs.ku.edu/software/surfseis/masw.html

Loke, M. H. (2004). 2-D and 3-D Electrical Imaging Surveys. http://citeseerx.ist.psu.edu/viewdoc/download?doi=10.1.1.454.4831\&rep=rep1\&type=p df

OpenStreetMap Contributors (2015). Planet Dump [Data File from \$Date of Database Dump\$]. https://planet.openstreetmap.org

Shanahan, P. (2004). 1.34 Waste Containment and Remediation Technology. Cambridge, MA: Massachusetts Institute of Technology. https://ocw.mit.edu

Shepard, E. M. (1898). A Report on Greene County: Missouri Geol. Survey, 1st Series (Vol. 12, pp. 13-245).

Silvester, P. P., \& Ferrari, R. L. (1990). Finite Elements for Electrical Engineers (2nd ed.). Cambridge: Cambridge University Press.

Tenenbaum, D. (2009). Trash or Treasure? Putting Coal Combustion Waste to Work. Environmental Health Perspectives, 117, A490-A497. https://doi.org/10.1289/ehp.117-a490

University of Kentucky Center for Applied Energy Research (2017). Bottom Ash EXplored-CCBs, Coal, Combustion, By-Products, Structural Fill, Clinker, Concrete Blocks-Kentucky Ash Education Site-UK CAER.

Vandike, J. E., \& Sherman, L. D. (1994). Hydrogeologic Investigation of the Fulbright Area, Greene County, Missouri. https://dnr.mo.gov/pubs/WR43.pdf

William, R., Thiery, R. G., Schuller, R. M., \& Subway, J. J. (1981). Coal Fly Ash: A Review of the Literature and Proposed Classification System with Emphasis on Environmental Impacts (pp. 1-78). Environmental Geology Notes. https://www.ideals.illinois.edu/bitstream/handle/2142/78929/coalflyashreview96royw.p df? sequence 
Zhao, R., \& Anderson, N. (2018). A Description of Field Setup and Common Issues in 2-D Electrical Resistivity Tomography Data Acquisition. International Journal of Science and Research, 7, 1061-1066. https://doi.org/10.21275/ART20193810

Zhao, R. (2018). Delineation of a Coal Combustion Residue Landfill and Underlying Karst Subsurface in Southwest Missouri Using ERT and MASW Surveys. Doctoral Dissertation, Rolla, MO: Missouri University of Science and Technology.

https://scholarsmine.mst.edu/doctoral_dissertations/2857 